\title{
Implementation of Average-Based Fuzzy Time Series Model in Forecasting Product Selling at Ainaya Boutique
}

\author{
Eva N. Ramadhani ${ }^{1, *}$ Agus M. Abadi ${ }^{2}$ \\ ${ }^{1}$ Graduate Programme of Mathematics Education, Faculty of Mathematics and Natural Sciences, Universitas Negeri \\ Yogyakarta, Indonesia \\ ${ }^{2}$ Department of Mathematics Education, Faculty of Mathematics and Natural Sciences, Universitas Negeri \\ Yogyakarta, Indonesia \\ ${ }^{*}$ Corresponding author.Email: evanur.2019@student.uny.ac.id
}

\begin{abstract}
Demand forecasting is needed in a company to find out the estimated level of demand in the future. Forecasting cannot be considered as an absolute one because there is no accurate forecasting. The forecasting accuracy level continues to be sought through forecasting development. One of those is applied through artificial intelligence. This study discusses the application of forecasting product selling using average-based fuzzy time series in Ainaya Boutique as the case of the study. The forecasting system with average-based fuzzy time series captures patterns from past data. In this study, the data used for forecasting is monthly selling data based on the last three years. This research uses five types of products that are sold the most in the boutique. The trial result of forecasting selling products during January 2017 December 2019 that uses the average-based fuzzy time series model show the result of the next month following data: the average error for the robe is $4.81 \%, 11.21 \%$ for the tunic, $8.78 \%$ for pashmina, $18.35 \%$ for khimar, and $9.72 \%$ for jeans. These results show that forecasting selling products in an Ainaya Boutique using the average-based fuzzy time series model has a high accuracy level.
\end{abstract}

Keywords: Forecasting, Fuzzy, Average-based Fuzzy Time Series.

\section{INTRODUCTION}

Selling forecasting is an activity that estimates the number of goods or services that are sold by the manufacturer, the distributor, and the marketing territory team for a specified period. Selling forecasting is a part of function management. It functions as one of the 'company's success contributors. When the selling prediction is accurate, the fulfilment of consumer demand can be sought on time. Customer satisfaction can be fulfilled, and the company can avoid lost selling and out of stock. Also, it prevents consumers from moving to competitors. On the other hand, the company can determine the policy decisions for production plans, supply goods, and cash flow. In other words, no company can avoid forecasting selling activities to carry out activities.

Sales forecasting can be done using several methods, including lead driven forecasting, opportunity stage forecasting, test market analysis forecasting, etc. Sales forecasting can also be done using fuzzy logic. A specific fuzzy application on time series data is known as fuzzy time series, time series model [1]. The fuzzy time series model is a dynamic process with linguistic values as its observation. Forecasting product selling is an estimation that contains uncertainty elements. These elements will be predicted using the fuzzy logic that is collected based on the previous historical data. The application of the fuzzy model in forecasting time series has widespread increasingly. The researchers have also been trying to improve the forecasting time series quality in many ways [2]. Song and Chisoom have studied the fuzzy application for the university ' 'enrolment's prediction [3-5]. A fuzzy time series model has been applied to predict d electricity demand's peak load [6]. It has been applied to predict the stock price [7-10]. Rodger [11] has used the fuzzy model to predict the need for natural gas and the cost of saving energy in public buildings. Chen and Hwang [12] have applied the fuzzy time series to predict area temperatures 
based on the previous temperature recorded data compiled in a certain period. Meanwhile, Birek, et al. [13] have applied the fuzzy time series for forecasting the water leakage in a water supply company.

Research using time series forecasting has been widely used, such as the Arima-box method, etc. Several methods require assumptions must be fulfilled. For example, the Arima-box method requires static data in terms of mean and variance. In reality, not all data can meet the required assumptions. For example, sales data at one of the well-known boutiques in the Sleman area, namely Ainaya Boutique. The type of product sales data at Ainaya Boutique is simple. So far, Ainaya Boutique predicts product sales using customer surveys with a relatively low level of accuracy. The difference between the prediction and sales results is quite far, which causes frequent stock vacancies and triggers consumers to switch to competitors. Based on the description above, the researcher chose to predict product sales at Ainaya Boutique by using the fuzzy time series method based on an average that does not contain assumptions, does not involve many variables, and has a high accuracy level. It makes calculations simpler[14].

\subsection{Forecasting with Average-based Fuzzy Time Series Model}

Fuzzy time series is a model is used for prediction. The advantage of the fuzzy time series model is that it does not require assumptions than other prediction models. Predictions with fuzzy time series using data in the past as a reference. Then, in the process, it will produce a new value displayed in the future. The resulting output is formed in these predictions results. The time series model is not too complicated, as it is easy to develop.

A lot of studies have been done related to predictions that use the time series model. One of those is a study conducted by Xihao and Yimin [14], the researchers predict Shanghai's compound index using the averagebased time series model. In that study, Xihao and Yimin compare the prediction results using the average-based fuzzy time series model that weighted the fuzzy time series model. The study results show that the averagebased fuzzy time series model has a smaller Mean Square Error (MSE) in 292.3 while the fuzzy time series model weights 436.2. The result of this study proves that the average-based fuzzy time series model has higher accuracy numbers. The accuracy of the average-based fuzzy time series model shows that the model can predict sales in a company.

\subsection{Intervals based on Average Values}

The average-based interval influences the number of fuzzy set determination used in the forecasting process. The steps to determine average-based interval are[14]:

1. Calculating the absolute difference between $D_{t+1}$ and $D_{t}(t=1, \ldots, n) . D$ is the actual data, and $t$ is the period, then the average value can be calculated.

2. Taking half of the average difference in the absolute value.

3. According to the obtaining values, keep the base values to the table, as seen in table 1[15].

Table 1. Base mapping of forecasting result

\begin{tabular}{|c|c|}
\hline Range & Base \\
\hline $0.1-1.0$ & 0.1 \\
\hline $1.1-10$ & 1 \\
\hline $11-100$ & 10 \\
\hline $101-1000$ & 100 \\
\hline
\end{tabular}

4. According to the base mapping forecasting result, rounding up the obtaining value is seen in the table to get the interval.

\subsection{Fuzzy Logical Relationship (FLR)}

If there is a relation $R(t, t+1)$, then $A_{i}(t+1)=$ $A_{i}(t) \times R(t, t+1)$ with the symbol $\times$ is an operator. $A_{i}(t+1)$ is caused by $A_{i}(t)$ [16]. Fuzzy logical relationships that exist between $A_{i}(t+1)$ and $A_{i}(t)$ are denoted by $A_{i}(t) \rightarrow A_{i}(t+1)$ where $A_{i}(t)$ is called the left-hand side and $A_{i}(t+1)$ is called the right-hand side[17].

\subsection{Fuzzy Logical Relationship Group (FLRG)}

The fuzzy logical relationship group in the averagebased fuzzy time series model, eliminates repetitive fuzzy logical relationships and combines fuzzy logical relationships with the same left-hand side into a group [18].

\subsection{Measurement of Forecasting Results}

Forecasting results are not always accurate. he forecasting techniques that are used do not necessarily compatible with the nature of the data. Therefore, it is crucial to have forecasting supervision. It can show whether the forecasting technique is used or not. Forecasting supervision helps to choose and determine more appropriate forecasting techniques. It works through determining the tolerance range that is occurred for the forecasting deviations. 
In principle, forecasting surveillance is done by comparing the forecasting results with the reality that occurs. The most appropriate forecasting technique to use is the one that produces the smallest deviation. The AFER and MSE models are used to determine the deviation magnitude that occurs in the forecasting data to the real data [12].

\subsubsection{Average Forecasting Error Rate (AFER)}

Average Forecasting Error Rate (AFER) is used to determine the irregularities magnitude in forecasting data to the actual data [6]. The AFER value is calculated using (1)

$A F E R=\frac{\sum_{i=1}^{n} \frac{\left|A_{i}-F_{i}\right|}{A_{i}}}{n} \times 100 \%$

$A_{i}$ are the actual values in the $i$-th data, $F_{i}$ are the forecasting result for the $i$-th data and $n$ is the number of data. The percentage result value to get is $100 \%$. The smaller error value happened means the accuracy goes better [19].

\subsubsection{Mean Square Error (MSE)}

Mean Square Error (MSE) is a model that is used to evaluate the forecasting model. Each error or is squared. Then, these are added up to the number of observations. This approach rules large forecasting errors because they are squared. This model produces moderate errors which are better for small mistakes. However, it sometimes makes a big difference. The MSE value is calculated using (2)

$M S E=\sum_{i=1}^{n} \frac{\left(A_{i}-F_{i}\right)^{2}}{n}$

where $A_{i}$ is the actual value in the $i$-th data, $F_{i}$ is the forecast value for the $i$-th data and $n$ is the number of observations [20].

\section{RESEARCH METHODS}

The data that is used in this study is monthly historical data. It is used to forecast the selling products in an Ainaya Boutique, located at Berbah-Kalasan, Street No.179, Yogyakarta, Indonesia, using the Average-based fuzzy time series model. The data is collected from January 2017 to December 2019. As the data is very confidential in this study, the Ainaya Boutique only provides data for 5 types of products in the last 3 years. The five products are robe, tunic, pashmina, khimar, and jeans. Those are the highest-demand and the best-selling products in this boutique.

The data is analysed by measuring the current selling. Then, forecasting these future conditions by using the Average-based fuzzy time series model. Measuring the current selling data means analysing current and previous conditions as a source of information to predict future conditions. This is because past circumstances will be repeated in the future. Selling data is used as a variable. It is used as input before making product selling forecasting [21].

The steps of the average-based fuzzy time series model related to figure 1[14]. The first is giving input for product selling data. Then, determine the fuzzy set, $U=$ $\left(D_{\text {min }}, D_{\text {max }}\right)$ the set of universes that have been inputted, determine the average interval length. The result will divide the universe into several fuzzy set subsets. The third step is to determine each data's membership level and convert it into the fuzzy linguistic values. The next step is determining the fuzzy logical relationships. The fuzzy logical relationships existed between $A_{i}(t+1)$ and $A_{i}(t)$ is denoted by $A_{i}(t) \rightarrow$ $A_{i}(t+1)$. The fifth step for the FLGR in the averagebased fuzzy time series model is eliminating repetitive fuzzy logical relationships. Then, combine the FLR with the same left-hand side into a group. The last step of the FLRG result is defuzzification. It is used to get predict result value [22].

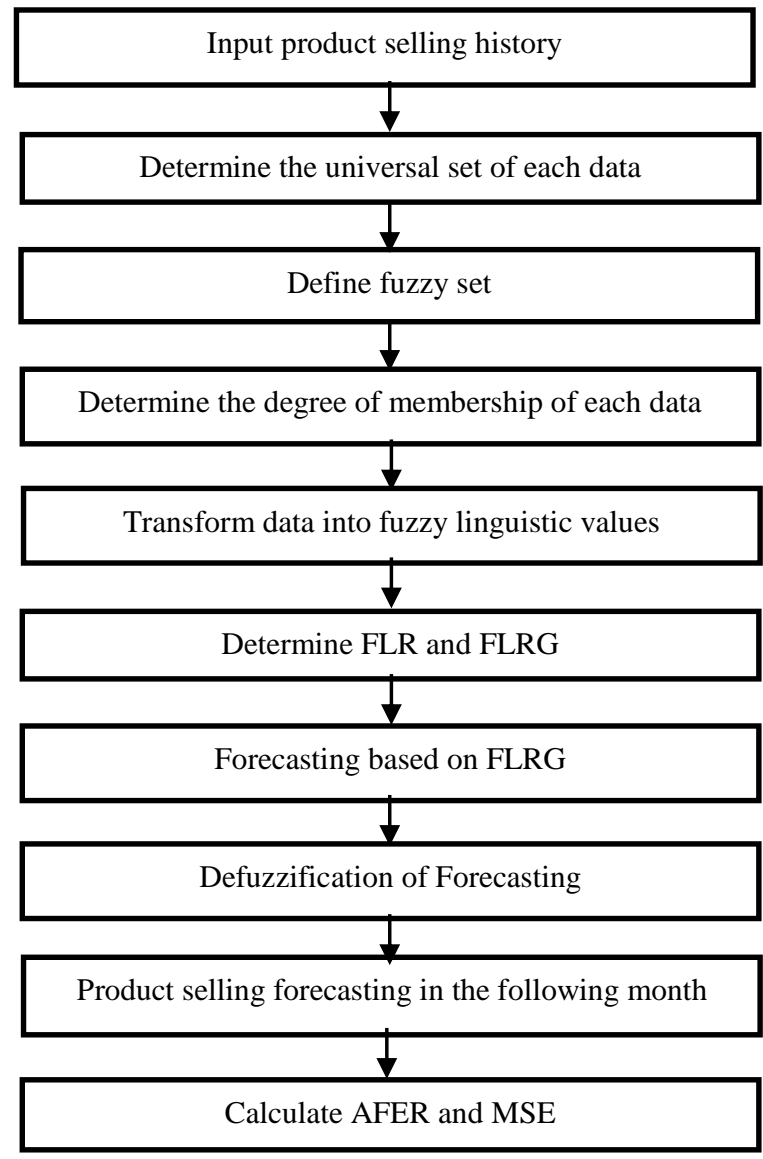

Figure 1 Forecasting process at Ainaya Boutique using average-based fuzzy time series 


\section{RESULTS AND DISCUSSION}

As shown in figure 1, the first step is to input the actual data. After the actual data entered, the next step is searching minimum and maximum values from the overall data. The minimum values is the lower of the universe while the maximum values is the upper limit of the universe. Based on actual data, the further explanation are $U_{\text {robe }}=[42,202], U_{\text {tunic }}=[45,178]$, $U_{\text {pashmina }}=[45,135], \quad U_{\text {khimar }}=[23,100] \quad$ and $U_{\text {jeans }}=[17,89]$. The third step is to determine the averaged base interval through the steps below:

a. Calculate the absolute difference for each data between months $n$ and $n+1$

b. Determine half of the average absolute difference

c. Determine the length of the interval by rounding up the obtaining value. Then adjust it for forecasting based on the mapping. It can be determined to 10.22 , included base 1 .

d. Rounding up 10.22 on base 1 , an average interval value of 10 is obtained.

After determining the base interval, the next step is to divide the universal set $U$ into the $u_{i}$ subset by making the average value as the range for each $u_{i}$ subset as in (3) [14].

$\left.u_{i}=\left(D_{\min }+(i-1) * r\right), D_{\max }+(i * r)\right)$

where $r$ is an interval based on predetermined mean value and $D_{\min }+(i * r)$ is not greater than $\left(D_{\max }+r\right)$

a. $U_{\text {robe }}=[42,202]$

b. Set $u_{i}$ as a subset of the $U_{i}$ where $(i=1,2, \ldots, n)$

$\left.\left.u_{i}=(42+(1-1) * 10)\right), 42+(1 * 10)\right)$

$=(42,52)$

$\left.\left.u_{2}=(42+(2-1) * 10)\right), 42+(2 * 10)\right)$

$=(52,62)$

$$
\text { : }
$$

$\left.\left.u_{16}=(42+(16-1) * 10)\right), 42+(16 * 10)\right)$

$=(192,202)$

It determines 16 linguistic values corresponding to 16 triangular fuzzy sets. It is written as $A_{1}, A_{2}$ to $A_{16}$ on the universal set $U_{\text {robe }}=[42,202]$. For example, the membership function of $A_{2}$ is shown in (4).

$$
f(x)_{A_{2}}=\left\{\begin{array}{l}
0 ; x \leq 47 \text { or } x \geq 62 \\
\frac{x-47}{8} ; 47<x \leq 55 \\
\frac{62-x}{7} ; 55<x<62
\end{array}\right.
$$

Figure 2 illustrates the 16 membership functions that are on the universal set $U_{\text {robe }}$.

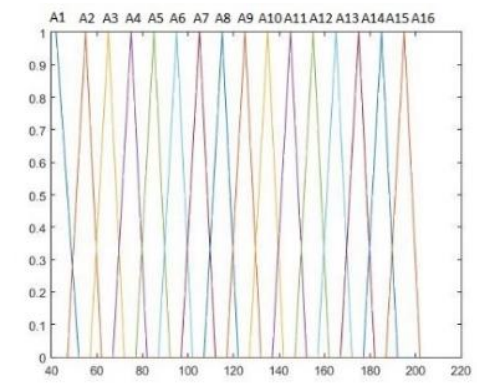

Figure 2 Fuzzy set of Robe products.

The next step is to define fuzzy membership into civil linguistic values. For example, the selling data of robe product in January 2017 is 78 . The calculation of fuzzy membership is

$$
\begin{aligned}
& f(x)_{A_{5}}=\frac{x-77}{8} \\
& f(78)=\frac{78-77}{8} \\
& f(78)=\frac{1}{8} \\
& f(78)=0.125
\end{aligned}
$$

Following the fuzzy membership calculation results, the robe product selling data in January 2017 includes the linguistic value, as seen in $A_{5}$.

Based on the table 2, the FLR is obtained. As the fuzzy logical relationship is seen as $A_{j} \rightarrow A_{k}$, whenever the product selling value in the $i$-month is $A_{j}$, then $i+1$ is $A_{k}$. If repeated relationship occurs, it will still count as once. The FLR from table 2 has been adjusted in order as shown in table 3 .

Table 2. Fuzzy membership value

\begin{tabular}{|c|c|c|}
\hline Month & Robe & Linguistic Value \\
\hline Jan-17 & 78 & $A_{5}$ \\
\hline Feb-17 & 89 & $A_{5}$ \\
\hline Mar-17 & 79 & $A_{5}$ \\
\hline Apr-17 & 64 & $A_{3}$ \\
\hline$\vdots$ & $\ldots$ & $\vdots$ \\
\hline Nov-19 & 100 & $A_{7}$ \\
\hline Dec-19 & 98 & $A_{7}$ \\
\hline
\end{tabular}


Table 3. Fuzzy logical relationship

\begin{tabular}{|c|c|}
\hline Time Series & FLR \\
\hline Jan 17-Feb 17 & $A_{5} \rightarrow A_{5}$ \\
\hline Feb 17-Mar 17 & $A_{5} \rightarrow A_{5}$ \\
\hline Mar 17-Apr 17 & $A_{5} \rightarrow A_{3}$ \\
\hline Apr 17-May 17 & $A_{3} \rightarrow A_{5}$ \\
\hline$\vdots$ & $\vdots$ \\
\hline Oct 19-Nov 19 & $A_{7} \rightarrow A_{7}$ \\
\hline Nov 19-Dec 19 & $A_{7} \rightarrow A_{7}$ \\
\hline
\end{tabular}

Based on the FLR in Table 3, the next step is to establish the FLRG by eliminating the same and recurring FLR. Then, form it as a group, as seen in table 4. The next step is doing the forecasting and defuzzification process based on FLRG as seen in table 5. To simplify the calculation, it is possible to calculate all possible values for each group from the fuzzification results.

The forecast defuzzification results for the group of $A_{1}$ in the left-hand side are $A_{1}$ and $A_{5}$. Whenever $A_{1} \rightarrow$ $A_{1}, A_{5}$ seen as fuzzy set with the maximum value of fuzzy membership, $A_{1}$ is found as the set of $u_{1}$. The maximum value for $A_{5}$ in the fuzzy membership is found in $u_{5}$ set. It means the values of $u_{1}$ and $u_{5}$ are 42 and 85 . The forecast results for the $t+1$ period is the average values of 42 and 85 . It is 68.5. The following numbers are summarized down below, as seen in Table 6 .

Table 4. Fuzzy logical relationship group

\begin{tabular}{|c|c|l|}
\hline No & Left-hand Side & \multicolumn{1}{|c|}{ Right-hand Side } \\
\hline 1 & $A_{1} \rightarrow$ & $A_{1}, A_{5}$ \\
\hline 2 & $A_{2} \rightarrow$ & $A_{1}$ \\
\hline 3 & $A_{3} \rightarrow$ & $A_{5}$ \\
\hline 4 & $A_{4} \rightarrow$ & $A_{7}$ \\
\hline 5 & $A_{5} \rightarrow$ & $A_{2}, A_{3}, A_{5}, A_{6}, A_{8}$ \\
\hline 6 & $A_{6} \rightarrow$ & $A_{1}, A_{7}, A_{8}, A_{12}$ \\
\hline 7 & $A_{7} \rightarrow$ & $A_{6}, A_{7}, A_{8}$ \\
\hline 8 & $A_{8} \rightarrow$ & $A_{4}, A_{5}, A_{6}, A_{7}, A_{8}$ \\
\hline 9 & $A_{12} \rightarrow$ & $A_{16}$ \\
\hline 10 & $A_{16} \rightarrow$ & $A_{8}$ \\
\hline
\end{tabular}

Table 5. Defuzzification

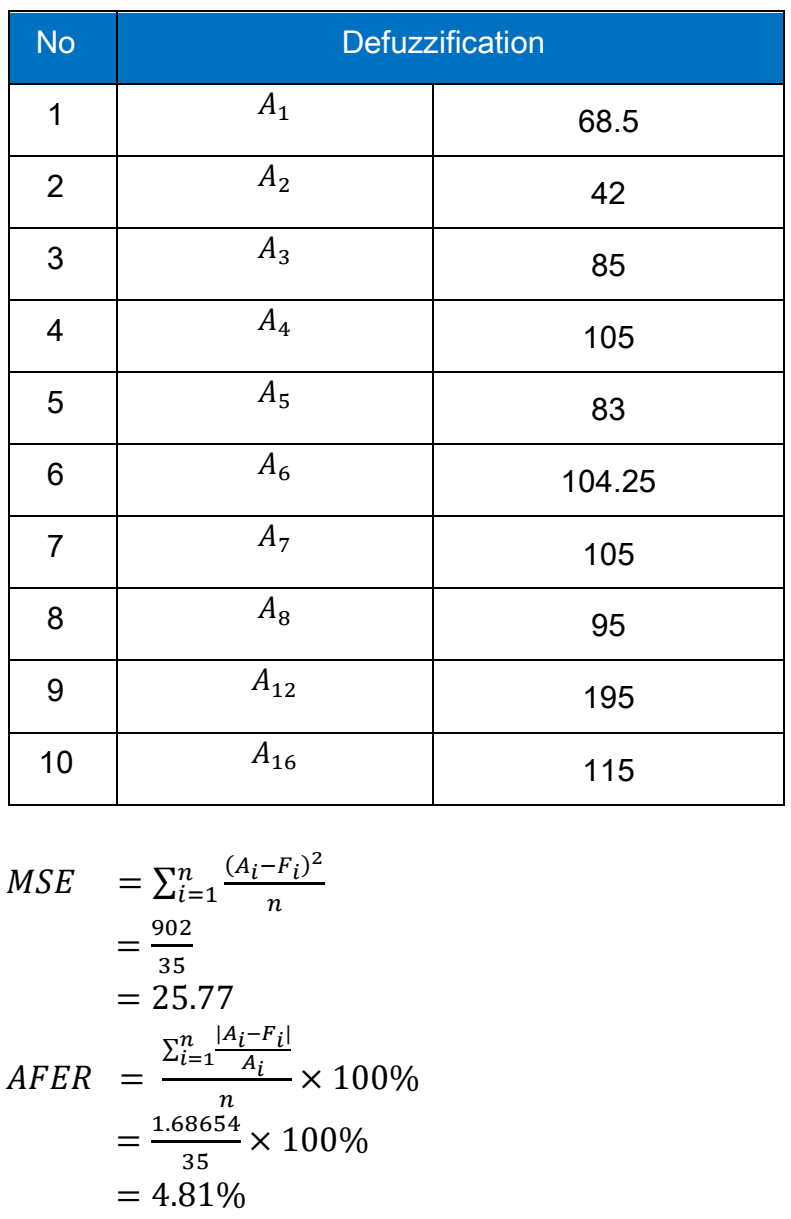

Furthermore, other product predictions are carried out with the same steps, such as predicting robe sales products. The results for forecasting the robe's selling in an Ainaya Boutique during 2017-2019 are presented in Table 7.

Among these five types of products, three types have relatively high accuracy levels. Those are the robe with an average error rate at $4.81 \%$, the forecasting accuracy at $95.19 \%$, pashmina with an average error rate at $9.78 \%$, and the forecasting accuracy at 91.22 and jeans' average error rate at $9.72 \%$ and the forecasting accuracy at $90.28 \%$.

As shown in Figure 3, the robe sales show a significantly increase in sales from June 2019 to July 2019. The increasing sales in an Ainaya Boutique happen from many factors. One of the factors is the sales that happened during Eid al-Fitr and Eid al-Adha. It helps the boasting sales for the robe in the boutique from June 2019 to July 2019. During the research, the number of tunic sales has increased from August 2019 to February 2020, as shown in Figure 4. During this period, the increasing sales for tunicare because the students and colleagues bought it for school and campus activities. 
Furthermore, the sales of Pashmina, Khimar, and Jeans have increased for specific months. The higher increasing sales happen every three months, as shown in Figure 5, Figure 6, and Figure 7. Based on interviews with Ainaya Boutique, the cases happen from several factors including the latest fashion trends.

When compared to sales forecasting conducted by Ainaya Butik using visitor surveys, forecasting product sales at Ainaya Butik using average-based fuzzy time series produces data with higher accuracy, so that it can be used as a reference for taking the next step for sales purposes.

\section{CONCLUSION}

The implementation of the average-based fuzzy time series model in the Ainaya Boutique from the product selling forecasting research shows that this model's calculation can predict the following months of product selling numbers. It is proven that the average-based fuzzy time series model can give a higher accuracy level applied for product selling forecasting during the last three years. A company can use the forecasting model that gives a higher accuracy level to prepare the materials' availability for order as the reference. It helps to avoid a product stock gap. Among five types of products, 3 of them have a relatively higher accuracy level. The robe with an average error rate enters at $4.81 \%$, and the forecasting accuracy numbers at $95.19 \%$. The average error rate numbers for pashmina are $9.78 \%$, while the forecasting accuracy result shows $91.22 \%$. The last one is jeans that show the average error rate at $9.72 \%$ and the forecasting accuracy level at $90.28 \%$.

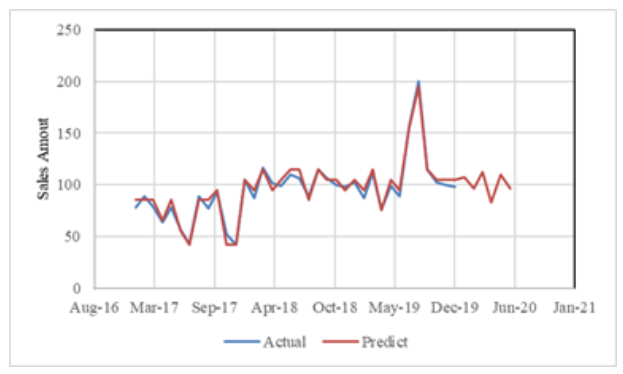

Figure 3 Selling data of Robe

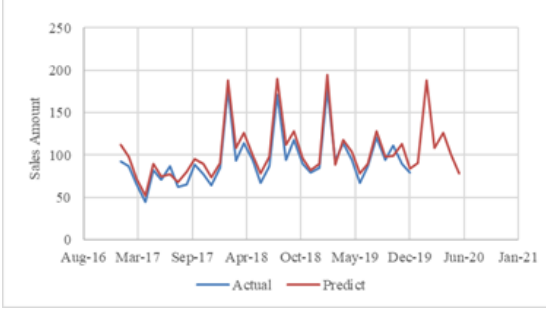

Figure 4 Selling Data of Tunic

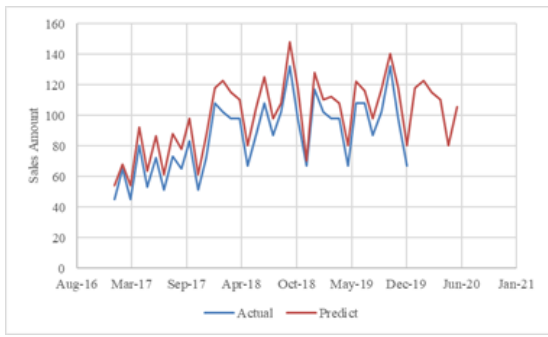

Figure 5 Selling Data of Pashmina

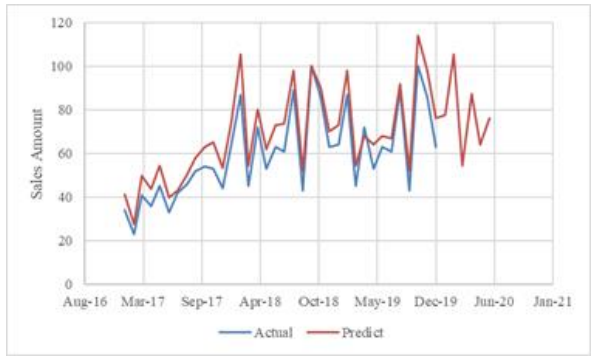

Figure 6 Selling data of Khimar

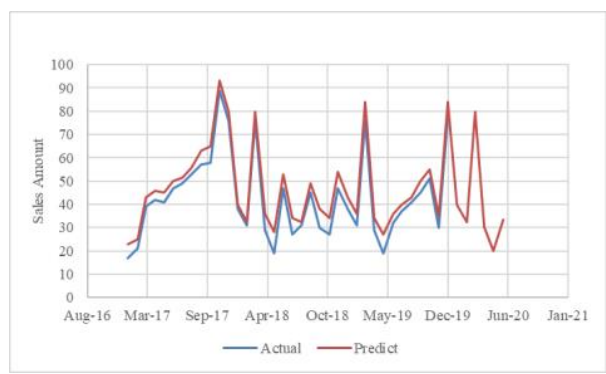

Figure 7 Selling data of Jeans 
Table 6. Robe product forecasting results using the Average-based fuzzy time series model

\begin{tabular}{|c|l|c|c|c|c|l|c|}
\hline No & Month & Selling & Fuzzy Membership & Forecasting & $\mid$ At-Fi| & $\mid$ At-Fi|/At & $(\text { At-Fi })^{2}$ \\
\hline 1 & Jan-17 & 78 & $A_{5}$ & 85 & 7 & 0.089744 & 49 \\
\hline 2 & Feb-17 & 89 & $A_{5}$ & 85 & 4 & 0.044944 & 16 \\
\hline 3 & Mar-17 & 79 & $A_{5}$ & 85 & 6 & 0.075949 & 36 \\
\hline$\vdots$ & & & & & & & $\vdots$ \\
\hline 36 & Dec-19 & 98 & $A_{7}$ & 105 & 7 & 0.071429 & 49 \\
\hline \multicolumn{2}{|l|}{ Total } & 3407 & & 3471 & 148 & 1.68654 & 902 \\
\hline
\end{tabular}

Table 7. Forecasting of Ainaya Boutique products selling in January 2017-December 2019

\begin{tabular}{|c|l|c|c|c|c|}
\hline No & Types of Products & Selling Forecasting & MSE & AFER & Accuracy \\
\hline 1 & Robe & 115 & 25.77 & $4.81 \%$ & $95.19 \%$ \\
\hline 2 & Tunik & 120 & 60.05 & $11.21 \%$ & $88.79 \%$ \\
\hline 3 & Pashmina & 89 & 47.03 & $8.78 \%$ & $91.22 \%$ \\
\hline 4 & Khimar & 93 & 98.25 & $18.34 \%$ & $81.66 \%$ \\
\hline 5 & Jeans & 83 & 52.07 & $9.72 \%$ & $90.28 \%$ \\
\hline
\end{tabular}

\section{ACKNOWLEDGMENTS}

We thank the Ainaya Boutique that gave permissions to use their sales data from January 2017 - December 2019 in this research.

\section{REFERENCES}

[1] N. Azizah, K. 'A'yun, T.W. Septiarini, D.U. Wutsqa and A.M. Abadi, Optimization of fuzzy inference system using table look-up method to predict white sugar price in the international market, Journal of Physics Conference Series 1097(1), 2018, DOI: $\quad \underline{10.1088 / 1742-}$ 6596/1097/1/012074

[2] S. Nurhayadi, Abdurakhman, A.M. Abadi, Fuzzy model optimization for time series data using a translation in the extent of mean error, Journal of Mathematics and Statatistic 10, 2014, pp 267-274, DOI: https://doi.org/10.3844/jmssp.2014.267.274

[3] Q. Song, B.S. Chissom, Fuzzy time-series and its models, Fuzzy Sets System 54(1), 1993a, pp 269277, DOI: $10.1016 / 0165-0114(93) 90372-\mathrm{O}$

[4] Q. Song, B.S. Chissom, Forecasting enrollment with fuzzy time series part I, Fuzzy Sets System 54, 1993b, pp 1-9, DOI: 10.1016/0165-0114(93)90355L

[5] Q. Song and B.S. Chissom, Forecasting enrolment with fuzzy time series part II, Fuzzy Sets System 62,
1994, pp 1-8, DOI: https://doi.org/10.1016/01650114(94)90067-1

[6] Z. Ismail, A. Yahya, K.A. Mahpol, Forecasting peak load electricity demand using statistics and rulebased approaches, American Journal of Applied Sciences 6, 2009, pp 1618-1625, DOI: https://doi.org/10.3844/ajassp.2009.1618.1625

[7] E. Egrioglu, PSO-based high order time invariant fuzzy time series model: Application to stock exchange data, Economic Modelling 38, 2014, pp 633-639, DOI: 10.1016/j.econmod.2014.02.017

[8] J.L. Kao, C.C. Chiu, C. Lu, J. Li Yang, Integration of nonlinear independent component analysis and support vector regression for stock price forecasting, Neurocomputing 99, 2013, pp 534-542, DOI: https://doi.org/10.1016/j.neucom.2012.06.037

[9] Nurhayadi, Subanar, Abdurakhman, A.M. Abadi, Fuzzy model translation for time series data in the extent of median error and its application, Applied Math. Sci 8, 2014, pp 2113-2124. DOI: 10.12988/AMS.2014.42114

[10] P. Singh and B. Borah, Forecasting stock index price based on M-factors fuzzy time series and particle swarm optimization, International Journal of Approximate Reason 55, 2014, pp 812-833, DOI: https://doi.org/10.1016/j.ijar.2013.09.014 
[11] J.A. Rodger, A fuzzy nearest neighbor neural network statistical model predicts demand for natural gas and energy cost savings in public buildings, Expert System with Application 41, 2014, pp 1813-1829, DOI: 10.1016/j.eswa.2013.08.080

[12] S.M. Chen, J.R. Hwang, Temperature forecasting using fuzzy time series, IEEE Transaction on Systems, Man, and Cybernetics-Part B: Cybernetics 30, 2000, pp 263-275.

[13] L. Birek, D. Petrovic, J. Boylan, Water leakage forecasting: The application of a modified fuzzy evolving algorithm, Applied Soft Computing 14, 2014, pp 305-315, DOI: https://doi.org/10.1016/j.asoc.2013.05.021

[14] S. Xihao, L. Yimin, Average-based fuzzy time series models for forecasting shanghai compound index, World Journal of Modelling and Simulation 4, 2008, pp 104-111.

[15] B.M. Samira, M. Saleh, Forecasting model based on fuzzy time series approach, The $11^{\text {th }}$ International Arab Conference on Information Technology, 2010.

[16] Y.H. Leu, C.P. Lee, Y.Z. Jou, A distance-based fuzzy time series model for exchange rates forecasting, Expert Systems with Applications 36, 2009, pp 8107-8114, DOI: https://doi.org/10.1016/j.eswa.2008.10.034

[17] K. A'yun, A.M. Abadi, F. Saptaningtyas, Application of weighted fuzzy time series model to forecast Trans Jogja passenger, International Journal of Applied Physics and Mathematics 5(2), 2015, pp 76-85, DOI: $10.17706 /$ ijapm.2015.5.2.76-85

[18] P. Singh, B. Borah, An efficient time series forecasting model based on fuzzy time series, Engineering Applications of Artificial Intelligence 26(10), 2013, pp 2443-2457, DOI: 10.1016/j.engappai.2013.07.012

[19] Sah, Melike \& Degtiarev, Konstantin Y 2005 Forecasting enrolment model based on first order fuzzy time series. MIEEE

[20] M. Stevenson, J. Porter, Fuzzy time series forecasting using percentage change as the universe of discourse, Proceedings of World Academy of Science, Engineering and Technology 55, 2009, pp 154-157.

[21] R. Abel, D.B. Jose, V. Enriqueta, Forecasting portfolio returns using weighted fuzzy time series method, International Journal of Approximate Reasoning 1, 2016, pp 1-12.

[22] T.A. Jilani, S.M.A. Burney, C. Ardil, Multivariate high order fuzzy time series forecasting for car road accidents, International Journal of Computer, Electrical, Automation, Control and Information Engineering 2, 2008, pp 2038-20 